\title{
Diverse metabolites of coral reef organisms*
}

\author{
Junichi Tanaka, Masayuki Kuniyoshi, Chiaki Tanaka, Hamad H. Issa, \\ Walter Balansa, Masahito Otsuka, Wahome P. Githige, and \\ Tatsuo Higa ${ }^{\ddagger}$
}

\author{
Department of Chemistry, Biology, and Marine Science, University of the Ryukyus, \\ Nishihara, Okinawa 903-0213, Japan
}

\begin{abstract}
A detailed mechanism for the spontaneous transformation of 2-chloro-1-hydroxyoctoda-3(8),5-dien-4-one, a metabolite of Portieria hornemanni, into 4,5-dimethylbenzo[b]furan was presented. Five new terpenoids have been isolated from the red alga Laurencia luzonensis. Five species of sponges yielded various metabolites: furanosesterterpenes from Ircinia sp., scalarane derivatives from Phyllospongia sp., polyketides from Theonella cf. swinhoei, a polyacetylene from Callyspongia sp., and cyclic depsipeptides from Suberites japonicus. Other new metabolites were sponge-derived secomanoalide derivative and imidazole alkaloids from nudibranchs, briarane class diterpenes from octocorals, and cyclofarnesylated hydroquinones, floresolides A-C, from an ascidian, Aplidium sp. Many of these compounds showed cytotoxicity.
\end{abstract}

\section{INTRODUCTION}

A coral reef in the tropical waters is a habitat of numerous species of fauna and flora. In terms of biodiversity, it is referred to as a rainforest of the sea and is particularly diverse in the species of sessile invertebrates belonging to the lower evolutionary levels. In this highly competitive environment, the organisms have developed various toxic substances as their survival strategies. Thus, the coral reef organisms have been the major targets of chemical studies which have yielded a large number of marine natural products since the 1970s. The majority of unique marine natural products known today are of coral reef origins. In our own research, we have reported a number of interesting molecules from algae and invertebrates of the coral reefs of Okinawa. We presented some of them at the $22^{\text {nd }}$ IUPAC International Symposium on the Chemistry of Natural Products [1] and at the $3^{\text {rd }}$ IUPAC International Conference on Biodiversity [2]. In this lecture, we present more recent results of our research on marine natural products.

\section{TERPENOIDS FROM ALGAE}

The tropical red alga Portieria (syn. Chondrococcus, Desmia) hornemanni has been investigated by several groups since the 1970s and reported to contain a variety of halogenated monoterpenes. In 1985, one of us (T.H.) reported the isolation of a labile cyclohexadienone (1), which spontaneously transformed into 4,5-dimethylbenzo[b]furan (2) and proposed a mechanism involving a hemiketal (3) as an intermediate of the transformation [3]. However, subsequent aromatization steps from $\mathbf{3}$ remained unexplained. More recently, we obtained additional cyclohexadienones from the alga and proposed fur-

\footnotetext{
*Paper based on a presentation at the $24^{\text {th }}$ International Symposium on the Chemistry of Natural Products and the $4^{\text {th }}$ International Congress on Biodiversity, held jointly in Delhi, India, 26-31 January 2004. Other presentations are published in this issue, pp. 1-344.

¥Corresponding author
} 
ther insight into the mechanism of the transformation [4]. In the aromatization of $\mathbf{3}$, if dehydration to form the benzenoid ring preceded dehydrochlorination, it should be equally possible to observe both 4,5-dimethylbenzo[b]furan (2) and 5,6-dimethylbenzo[b]furan (4) as products (Scheme 1). However, since the sole observed product was $\mathbf{2}$, we are now convinced that the first step of the aromatization is to involve $\mathrm{E}_{1}$ type elimination of the chloride ion followed by concomitant migration of a methyl group to the $\mathrm{C}-4$ position. This allows the formation of the observed product only in the next step, 1,4-elimination of a water molecule, to aromatize both rings simultaneously as shown in the right-hand side of Scheme 1.

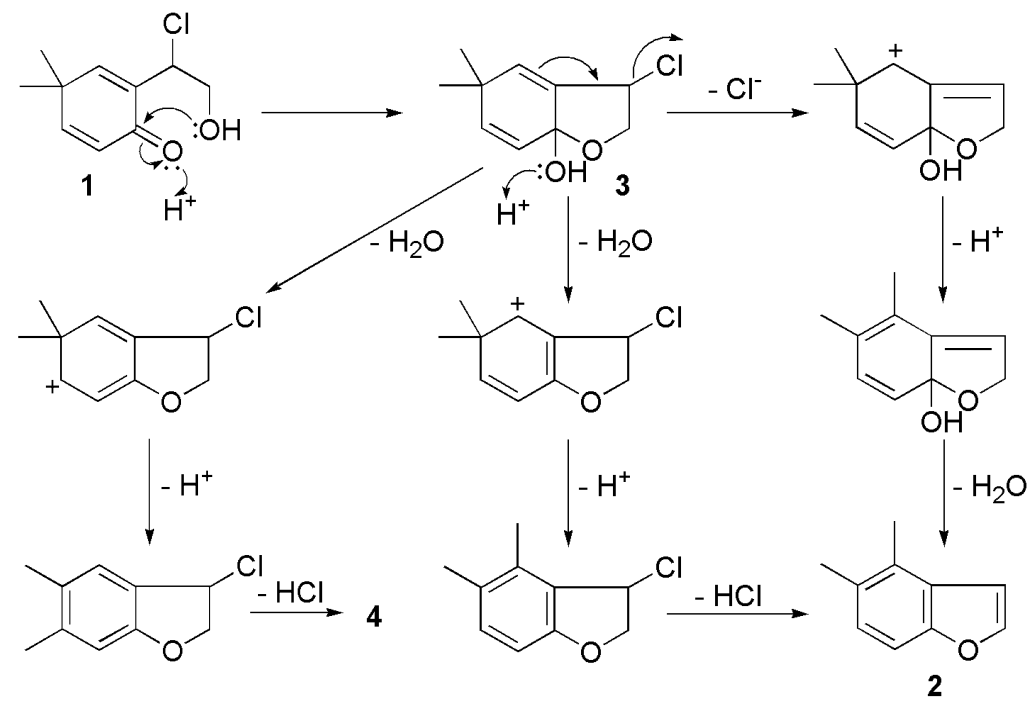

Scheme 1 Proposed mechanism for the transformation of $\mathbf{1}$ to $\mathbf{2}$. The most plausible route is cyclization of $\mathbf{1}$ to $\mathbf{3}$ followed by aromatization through elimination of $\mathrm{Cl}^{-}$prior to dehydration.

We recently reported the isolation and structure elucidation of several new terpenoids from the red alga Laurencia luzonensis, which had never been chemically investigated prior to our work [5]. Further study on the alga gave rise to additional new terpenoids, including compounds 5-9. The biosynthetic relationship of some of these compounds is proposed as shown in Scheme 2. Luzonensol, isolated from the present species for the first time, appears to be a key intermediate in the biosynthesis of many of these compounds. Luzodiol (9) is a diterpene having an unprecedented skeleton.<smiles>CC(CBr)=C1C[C@H]2C(C)(C)[C@@H](Br)CC[C@]2(C)O1</smiles>

6<smiles>CC1(C)[C@@H](Br)CC[C@@]2(C)OC(CBr)[C@](C)(O)CC[C@H]12</smiles>

3,4-Epoxypalisadin B (7)

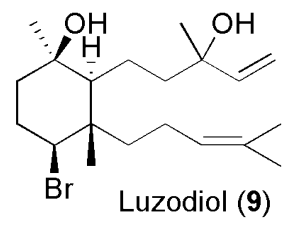




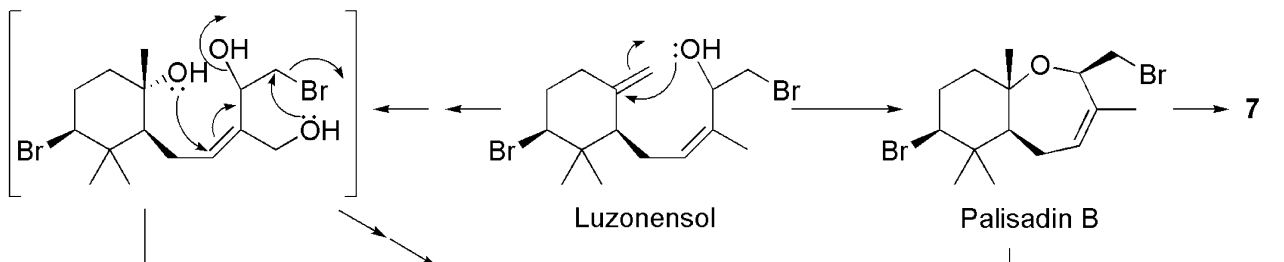<smiles>CCC1(C)C(Br)CCC2(C)OC(C3=CCOC3)CC21</smiles>

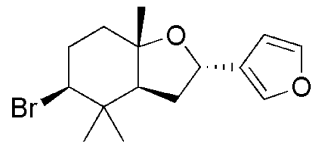

Luzofuran (5)<smiles>CC1(C)[C@@H](Br)CC[C@@]2(C)O[C@H]3COCC3=CC[C@@H]12</smiles>

Palisadin A<smiles>CC1(C)[C@@H](Br)CC[C@]2(C)O[C@H]3CO[C@@H](O)[C@H]3CC[C@H]12</smiles>

15-Hydroxypalisadin A (8)

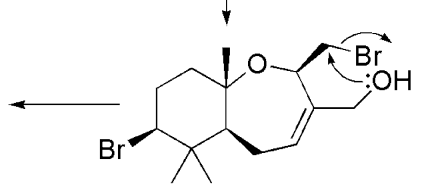

15-Hydroxypalisadin (known from $L$. cf. palisada)

Aplysistatin

Scheme 2 Biosynthetic relationship among some sesquiterpenes of Laurencia luzonensis.

\section{CYTOTOXIC SESTERTERPENES FROM SPONGES}

Sesterterpenoids are a relatively small group of compounds of which significant numbers are from marine sources. Two series of cytotoxic sesterterpenes have recently been obtained from two species of sponges: one series (10-14) from Ircinia sp. collected in Okinawa [6] and the other series (15-21) from an Indonesian collection of Phyllospongia sp. [7]. All of these compounds exhibited moderate cytotoxicity against KB cells. The structures were determined mainly by spectroscopic data. The absolute structures for the furanoterpenes $\mathbf{1 0}$ and $\mathbf{1 1}$ were elucidated by chemical degradation, and those (C-8, C-18) of 12-14 are based on analogy.<smiles>[Z20]C1=C(O)C(C)=C(O)/C1=C\[C@H](C)CCC/C(C)=C/C=C/[C@@]1(C)CCCc2ccoc21</smiles>

11: $10 E, 12 E$<smiles>C/C(=C/C=C/[C@@]1(C)CCCc2ccoc21)CCC[C@H](C)CC(=O)C(O)[C@H](C)Cl</smiles>

13: $22,23-$ anti

14: 22,23-syn

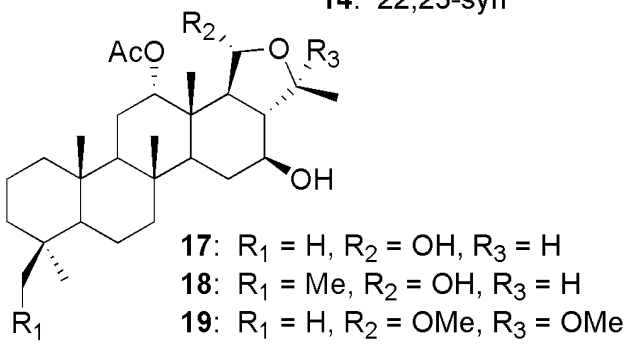<smiles>CC[C@H](O)C(=O)C[C@H](C)CCC/C(C)=C\C=C\[C@]1(C)CCCc2ccoc21</smiles>

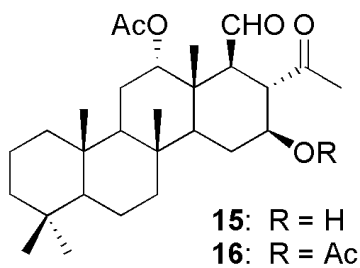

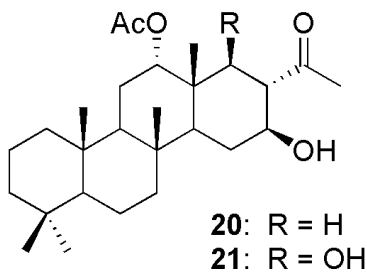


The compounds 15-21 belong to the scalarane class and are based on $\mathrm{C}_{25}$ to $\mathrm{C}_{27}$ (dihomoscalarane) skeletons. The structure of $\mathbf{1 5}$ was confirmed by X-ray analysis. Scalaranes are reported to have a variety of biological activities including cytotoxicity, anti-inflammation, anti-HIV, and antimicrobial properties.

\section{POLYKETIDES FROM SPONGES}

A series of unique polyketides, bitungolides A-F (22-27) have been isolated from an Indonesian sponge, Theonella cf. swinhoei [8]. The structure of bitungolide A (22) was elucidated by X-ray and the rest by spectroscopic correlation. Although bitungolides are the first such compounds from marine sources, they share the same structural elements with those of microbial metabolites, pironetin (28) known as a microtubule-targeting drug [9] and phoslactomycin (29), a phosphatase inhibitor [10]. Bitungolides showed moderate and selective activity against dual-specificity phosphatase, but no activity against microtubules.

Another Indonesian sponge, Callyspongia sp., yielded a new polyacetylene $(\mathbf{3 0}),[\alpha]_{\mathrm{D}}{ }^{25}-7.9^{\circ}$ $\left(\mathrm{CHCl}_{3}\right)$, which exhibited moderate cytotoxicity against NBT-II cells. The structure was deduced from<smiles>CC[C@H]1C=CC(=O)O[C@H]1[C@H](C)C[C@H](O)[C@H](O)C[C@H](O)/C=C/C=C/c1cccc(O)c1Cl</smiles>

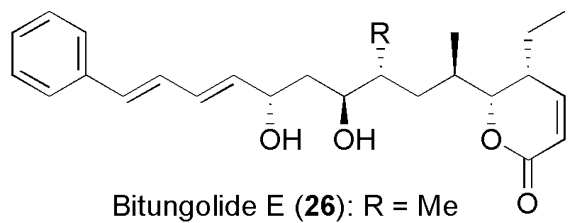

Bitungolide $\mathrm{B}(23): 12 E, 14 E$

Bitungolide C (24): 12Z, $14 E$

Bitungolide D (25): 12E, $14 Z$

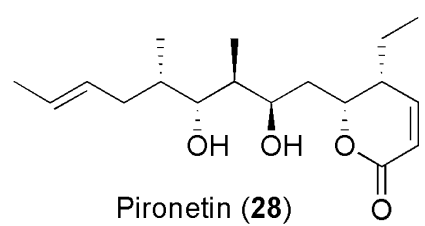<smiles>CCC1C=CC(=O)OC1/C=C/C(O)(CCN)C(CC(O)/C=C/C=C/C1CCCC(OC(=O)C(C)C)C1)OP(=O)(O)O</smiles>

Phoslactomycin A (29)

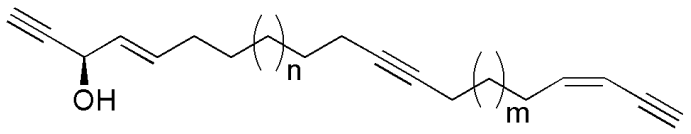

30: $m=1, n=13$

31: $m+n=18$

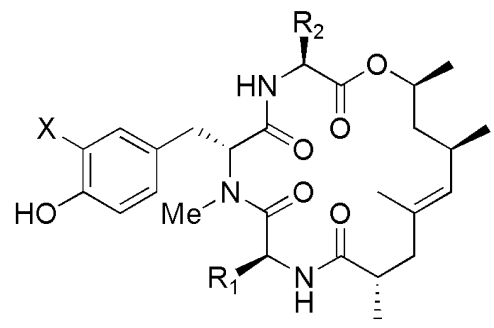

Seragamide $A$ (32), $R_{1}=\mathrm{Me}, \mathrm{R}_{2}=\mathrm{CH}(\mathrm{OH}) \mathrm{CH}_{3}, \mathrm{X}=\mathrm{I}$ Seragamide $B$ (33), $\mathrm{R}_{1}=\mathrm{Me}, \mathrm{R}_{2}=\mathrm{CH}(\mathrm{OH}) \mathrm{CH}_{3}, \mathrm{X}=\mathrm{Br}$ Seragamide $C$ (34), $R_{1}=M e, R_{2}=\mathrm{CH}(\mathrm{OH}) \mathrm{CH}_{3}, X=\mathrm{Cl}$ Seragamide $D$ (35), $R_{1}=H, R_{2}=C H(O H) C_{3}, X=1$ Geodiamolide $A(37), R_{1}=R_{2}=M e, X=1$

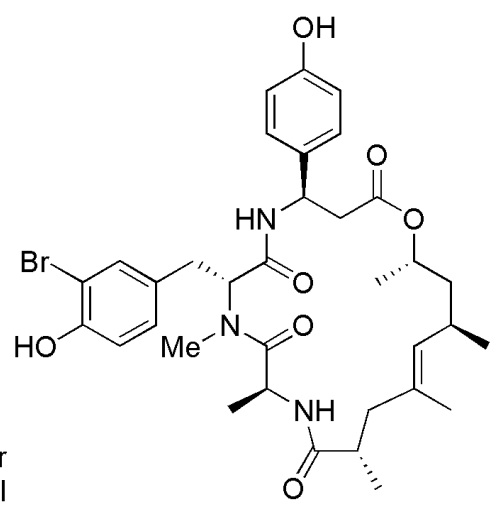

Geodiamolide I (36) 
spectroscopic data and the absolute configuration through MTPA esters. It has three acetylenic bonds on $\mathrm{C}_{31}$ chain and resembles the known callyspongins (e.g., 31) [11].

\section{CYTOTOXIC DEPSIPEPTIDES FROM A SPONGE}

An extract of the yellow sponge Suberites japonicus from Okinawa showed cytotoxicity in an assay against NBT-II cells. Separation of the extract gave rise to new cyclic depsipeptides named seragamides A-D (32-35) and the known related compound geodiamolide I (36) [12]. The gross structure of seragamide $\mathrm{A}(32),[\alpha]_{\mathrm{D}}{ }^{27}+45.6^{\circ}$, was secured by NMR analysis and the configurations for the amino acids L-Ala and L-Thr by Marfey method. The absolute stereochemistries for the iodo-Tyr and (4E)-8-hydroxy-2,4,6-trimethylnonenoic acid moiety are assumed to be the same with those of known related compounds, and confirmation study is now under way. A main structural difference between seragamides and most of geodiamolides (i.e., 37) is the presence of L-threonine in a place of L-alanine in the latter. Geodiamolides and related jaspamide (jasplakinolide) are known to have a wide range of biological activities, including potent cytotoxicity and antifungal property. Jaspamide having an effect on actin polymerization is now an important research tool in cell biology. Preliminary examination suggests that seragamides also affect actin polymerization.

\section{SPONGE-DERIVED METABOLITES FROM NUDIBRANCHS}

It is well established that defensive substances of shell-less mollusk nudibranchs are mainly the metabolites sequestrated from their prey organisms. Many compounds have been described from nudibranchs. Some of them are found in the same chemical forms as in their diet and some in slightly modified structures. The dorid nudibranch Chromodoris willani found infesting on a sponge, Luffariella sp., contained dehydroxysecomanoalide $(\mathbf{3 8}),[\alpha]_{\mathrm{D}}{ }^{25}-8.7^{\circ}$, a new derivative of the known secomanoalide (39). The structure was secured by spectroscopic analysis and the absolute configuration by the MTPA method.

The nudibranch Notodoris citrina was observed infesting on a yellow sponge, Leucetta sp. Examination of the constituents of this species gave rise to three new imidazole alkaloids (40-42) belonging to the class of naamine. Comparison of the metabolites with those obtained from the infested sponge suggested that the nudibranch modified original metabolites by additional $\mathrm{N}$-methylation.

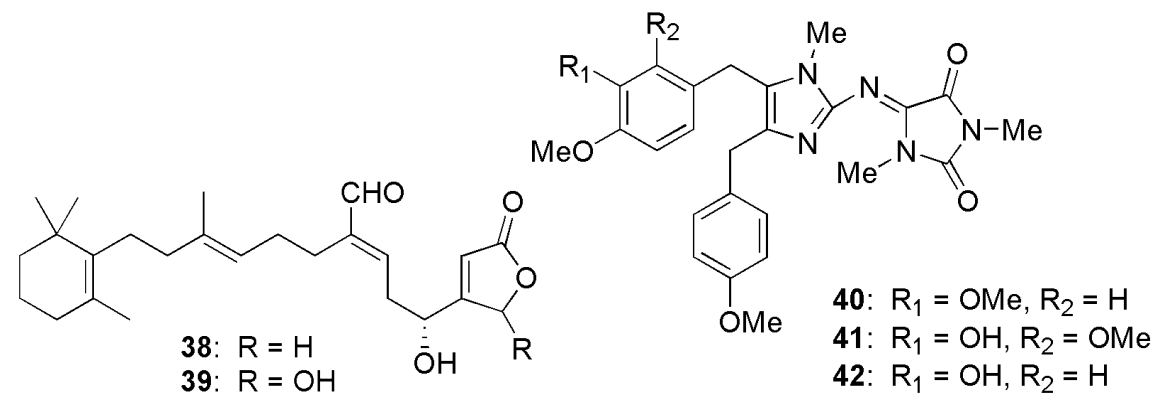

\section{BRIARANE DITERPENES FROM OCTOCORALS}

Briaranes are a class of diterpenes characteristic of some species of octocorals. More than $300 \mathrm{com}-$ pounds have been reported. These compounds are based on a highly oxygenated bicyclic skeleton composed of six- and ten-membered rings. They usually contain a $\gamma$-lactone, a chlorine atom, and more than two acetoxy groups. When we examined the constituents of the gorgonian Ellisella sp. from Okinawa, we obtained four new (43-46) and two known briaranes. Compounds 43 and 45 caused the NBT-II cells to form multinuclei, suggesting their action on cytoskeletal protein. 
A sea pen, Pteroeides sp. from Indonesia, furnished four new (47-50) and two known briaranes. The chlorine atom in these compounds is usually found at C-6, and a compound having it migrated to the allylic position as in $\mathbf{4 9}$ is rare, although not unprecedented. None of the briaranes $\mathbf{4 7 - 5 0}$ showed cytotoxicity against $\mathrm{KB}$ cells.

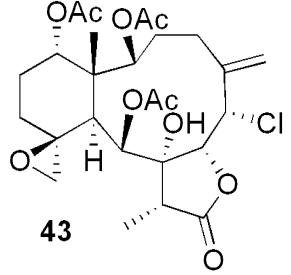

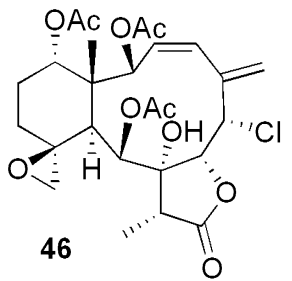

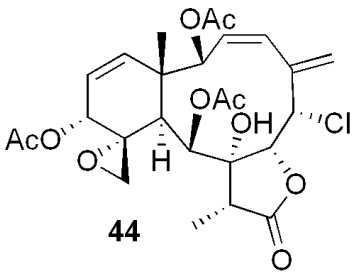

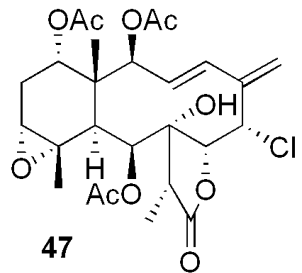

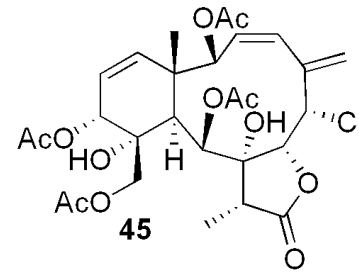

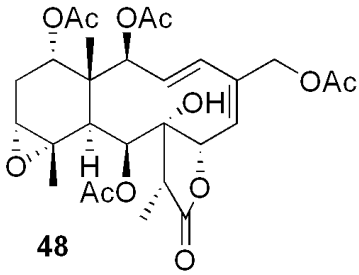

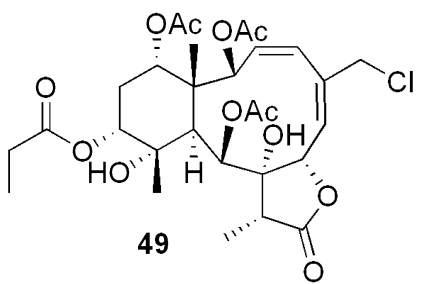

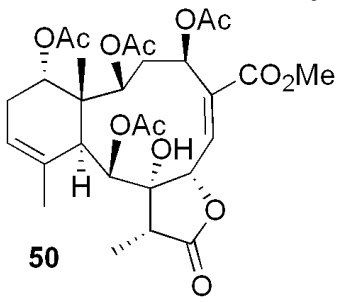

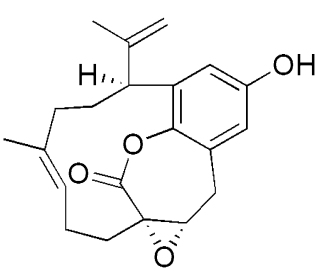

Floresolide A (51)<smiles>C=C(C)[C@H]1CCC(C)=CCCC1=CCc1cc(O)cc2c1OC(=O)C2</smiles>

Floresolide B (52)

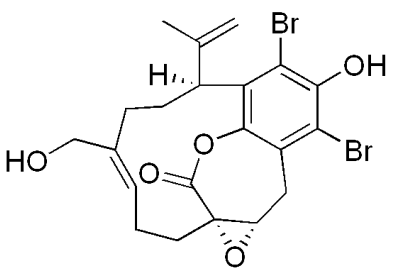

Floresolide C (53)

\section{METABOLITES FROM AN ASCIDIAN}

Three new meroterpenoids, floresolides A-C (51-53), have been isolated from an Indonesian ascidian, Aplidium sp. The structures were determined by spectroscopic and X-ray analysis [13]. These compounds are related to the class of compounds known as longithorones and longithorols, but their unique features are in the presence of an $\varepsilon$-lactone bridging the aromatic ring and a [10]metacyclophane band and of a double bond or an epoxy function at the bridgehead, confining the cyclophane ring into a relatively rigid system. Floresolides showed moderate cytotoxicity against KB cells.

\section{ACKNOWLEDGMENTS}

We thank Drs. M. Kobayashi and S. Aoki, Osaka University, and Dr. G. Marriott, University of Wisconsin-Madison, for cytotoxicity and MDR assay, Dr. H. Osada, Riken, for phosphatase assay. We 
appreciate Dr. R. Rachmat, Dr. A. Setiawan, and Mr. A. Trianto, for collection of Indonesian marine organisms.

\section{REFERENCES}

1. T. Higa, J. Tanaka, I. I. Ohtani, M. Musman, M. C. Roy, I. Kuroda. Pure Appl. Chem. 73, 589 (2001).

2. T. Higa, M. C. Roy, J. Tanaka, I. I. Ohtani. In Biodiversity: Biomolecular Aspects of Biodiversity and Innovative Utilization, B. Sener (Ed.), p. 167, Kluwer Academic/Plenum Publishers, New York (2002).

3. T. Higa. Tetrahedron Lett. 26, 2335 (1985).

4. M. Kuniyoshi, N. Oshiro, T. Miono, T. Higa. J. Chin. Chem. Soc. 50, 167 (2003).

5. M. Kuniyoshi, M. S. Marma, T. Higa, G. Bernardinelli, C. W. Jefford. J. Nat. Prod. 64, 696 (2001).

6. H. H. Issa, J. Tanaka, T. Higa. J. Nat. Prod. 66, 251 (2003).

7. M. C. Roy, J. Tanaka, N. de Voogd, T. Higa. J. Nat. Prod. 65, 1838 (2002).

8. S. Sirirath, J. Tanaka, I. I. Ohtani, T. Ichiba, R. Rachmat, K. Ueda, T. Usui, H. Osada, T. Higa. J. Nat. Prod. 65, 1820 (2002).

9. M. Kondoh, T. Usui, S. Kobayashi, K. Tsuchiya, K. Nishikawa, T. Nishikiori, T. Mayumi, H. Osada. Cancer Lett. 126, 29 (1998).

10. S. Fushimi, S. Nishikawa, A. Shimazu, H. Seto. J. Antibiotics 42, 1019 (1989).

11. F. Rooney and R. J. Capon. Lipids 33, 639 (1998).

12. W. F. Tinto, A. J. Lough, S. McLean, W. F. Reynolds, M. Yu, W. R. Chan. Tetrahedron 54, 4451 (1998).

13. H. H. Issa, J. Tanaka, R. Rachmat, T. Higa. Tetrahedron Lett. 44, 1243 (2003). 